\title{
Human factors: Predictors of avoidable wilderness accidents?
}

\author{
R De Decker, ${ }^{1} \mathrm{MSc}, \mathrm{MB} \mathrm{ChB}, \mathrm{DCH}, \mathrm{FC}$ Paeds (SA), Cert Med Genetics (SA), G Tölken, ${ }^{2} \mathrm{MA}$; \\ J Roos, ${ }^{3} \mathrm{MB}$ ChB, DA (SA), FCA (SA), MMed (Anaes)
${ }^{1}$ Department of Paediatrics and Child Health, Faculty of Health Sciences, University of Cape Town and Red Cross War Memorial Children's Hospital, Cape Town, South Africa; and International Commission for Alpine Rescue Emergency Medicine Commission representative for the Mountain Club of South Africa Mountain Rescue team, Cape Town, South Africa
${ }^{2}$ WildMedix, Cape Town, South Africa; and Mountain Rescue, Hottentots-Holland Section - Mountain Club of South Africa, Cape Town, South Africa
${ }^{3}$ Department of Anaesthesia, Mitchell's Plain Hospital, Cape Town, South Africa; and South African Red Cross Air Mercy Service, Cape Town, South Africa

Corresponding author: R De Decker (rik.dedecker@uct.ac.za)

\begin{abstract}
A common misconception is that wilderness adventure travel is risky owing to the nature of the objective dangers that are encountered, such as avalanches, rock falls, flash floods, failure of technical equipment and so forth. However, when one critically examines the proximal causes of wilderness accidents, even those caused by such 'objective dangers', it is apparent that many are due to 'human factors' or nontechnical skills. These are broadly defined as the continuous process of identifying and avoiding the activities, interactions and decisions that may jeopardise safe and effective response to adverse events. Objective dangers and adverse events are unavoidable, but the response to them is governed by how team dynamics, leadership and followership modes, situational awareness and experience may mitigate these risks or manage their consequences effectively. On the other hand, ignoring human factors during wilderness travel is predictive of wilderness accidents. This article outlines how an awareness of human factors may be used to reduce the risks of adventure travel significantly.
\end{abstract}

S Afr Med J 2017;107(8):669-673. DOI:10.7196/SAMJ.2017.v107i8.12677

'Experience is what you get when you need it most.' (Unknown origin)

\section{Scenario}

Under the leadership of Pete, a ski-mountaineering guide, a group of six skiers make an early start from the Grands Montets cable car station above Chamonix - the start of the week-long Haute Route ski tour to Zermatt in Switzerland. On the big $(2200 \mathrm{~m})$ but easy descent to the Argentière glacier, differences in the skiing competencies of the team members are already noticeable. Opting to reach the Trient hut that evening in one big push, they agree to forego an early finish to the day at the nearby Argentière hut. Then, on the ascent up the Chardonnet glacier to the Col de Chardonnet, their skill differences are further pronounced by the technical challenges of doing kick turns on the steep, frozen snow. To the growing irritation of the competent Sebastian, two of the skiers, Jo and Dave, have to be shown how to use their ski crampons effectively. Reaching the Col, the team now faces one of the steepest descents on the Haute Route, usually done with a rope belay.

There is some delay while Pete explains that he wants them all to sideslip the descent while roped, but again Jo and Dave are uncertain precisely how this should be done. Sebastian then notes with agitation that the mountaintops have disappeared into cloud, and exclaims: 'Let's just ski down! We are wasting time!' Pete simply ignores him.

Then, without further ado, and mumbling with clear irritation about the 'incompetence' of the others, Sebastian launches off the Col on his skis. He manages a few deft, tight turns in the narrow couloir, but then catches an edge and tumbles out of sight. The team looks on with shock at his abrupt action, but then shock turns to horror when Sebastian can be seen sliding to a stop on the slope below the couloir. His skis are gone, and his left leg is at an impossible angle. A blood-curdling scream comes up from below and echoes from the shrouded cliffs around them, sharply emphasising the rapid change from a sunny, fun day to a grey nightmare. The Trient hut, on the other side of the Fenetre de Saleina and the Trient glacier, now seems very, very far away ...

\section{Background}

One's first reaction is to 'blame' Sebastian for his 'idiotic' behaviour. His needlessly impulsive act has not only caused him serious injury, but also thrust the group into a precarious situation. They need to seek urgent rescue from their remote location in rapidly deteriorating conditions, putting themselves at more risk. Yet, on reflection, perhaps one could ask:

- What really caused the accident?

- Could it have been avoided?

- How?

And perhaps one should think, before the outset of any wilderness trip:

- Can one predict/forecast accidents or high-risk situations?

- What are those predictors?

- If recognised, how can they be mitigated?

- What specific leadership roles or actions are required to avoid risk and accidents?

- What are followership roles? How and when should followers speak up when leadership is below par?

These questions should be addressed at the outset and on an ongoing basis during all stages of any wilderness excursion. How is this done, and where do these non-objective dynamics fit into mitigation of the obvious and compelling risks of wilderness adventures?

There are at least three important and distinct sets of factors that may impact on the safety and efficiency of wilderness activities: 
environmental factors, technical skills, and non-technical skills, otherwise known as human factors (HFs). While much attention is usually paid to the first two categories (is the weather OK, how old are your ropes, what is your skill level?), the third - HFs - is often disregarded. In many, if not most, instances of serious medical problems in the wilderness, it is precisely the HFs that are most important in risk prevention and mitigation. Despite HFs being distinct from the actual 'agents' of accidents, such as rock falls, avalanches or a siphon in a whitewater river, they have been clearly shown to be the most common cause of accidents. A meticulous review $^{[1]}$ of skydiving accidents in the USA clearly showed that as many as $86 \%$ of all fatal skydiving accidents are caused by HFs, and not environmental or technical factors. This article will focus on why and how HFs are the ultimate cause of accidents, and how this knowledge can reduce risks in the wilderness environment.

Remarkably little has been written about the role of HFs in the wilderness environment, ${ }^{[2,3]}$ but there is a vast literature on their causative risks in aviation ${ }^{[4]}$ and more recently in healthcare..$^{[5-7]}$ However, unlike healthcare, in aviation and wilderness adventures practitioners share a commonality: they are personally involved in the accidents. Nonetheless, even in healthcare, behavioural factors of the practitioner or care team may be the ultimate cause of accidents. Therefore, much of what is written on HFs in these diverse settings can be applied to causes of accidents in the wilderness.

\section{Human failure}

It is perceived that most accidents are caused by human errors, but human mistakes have a complex causality themselves. Using Fig. 1, we are able to classify Sebastian's error as a deliberate exceptional violation (breaking the rules in an attempt to solve an acute problem) and therefore perceived with shock by his teammates. Yet we can argue that Pete could probably have avoided Sebastian's impulsive behaviour by earlier assertive action. Pete's fault can be classified as an inadvertent thinking error due to a knowledge-based mistake (lacking the insight and experience to recognise deteriorating circumstances). As a guide, Pete should have known that frustration may induce irrational behaviour in some people. On the other hand, the other team members may be blamed for a rule-based inadvertent thinking error (they should have been aware that they should speak up in the absence of good leadership). Also, the team should have known that safety is not the sole responsibility of Pete as team leader. All these errors by Pete and his team members were proximal to and directly led to the collective failure in avoiding Sebastian's 'final' irrational action that 'caused' their precarious situation.

Human errors are unavoidable ('to err is human'), and are generally executed within a context or system that may be adapted to prevent such errors from happening in the first place. Sebastian's error was probably avoidable, but what could have been different in the team's context or system to predict and avoid this accident? Is it possible, during all wilderness excursions, to monitor the nonconcrete, almost intangible HFs at work in a group? And will an acute awareness of these factors allow one to predict when risks are rising, and an accident is about to happen?

\section{Human factors}

Besides the many recognisable objective dangers of the wilderness environment and the (very rare) failure of technical equipment, there is a third causative component to consider when trying to understand why things go badly wrong: the knowledge, recognition and correct interpretation of human (or non-technical, subjective) factors.

There are several broad definitions of HFs commonly employed in various contexts:

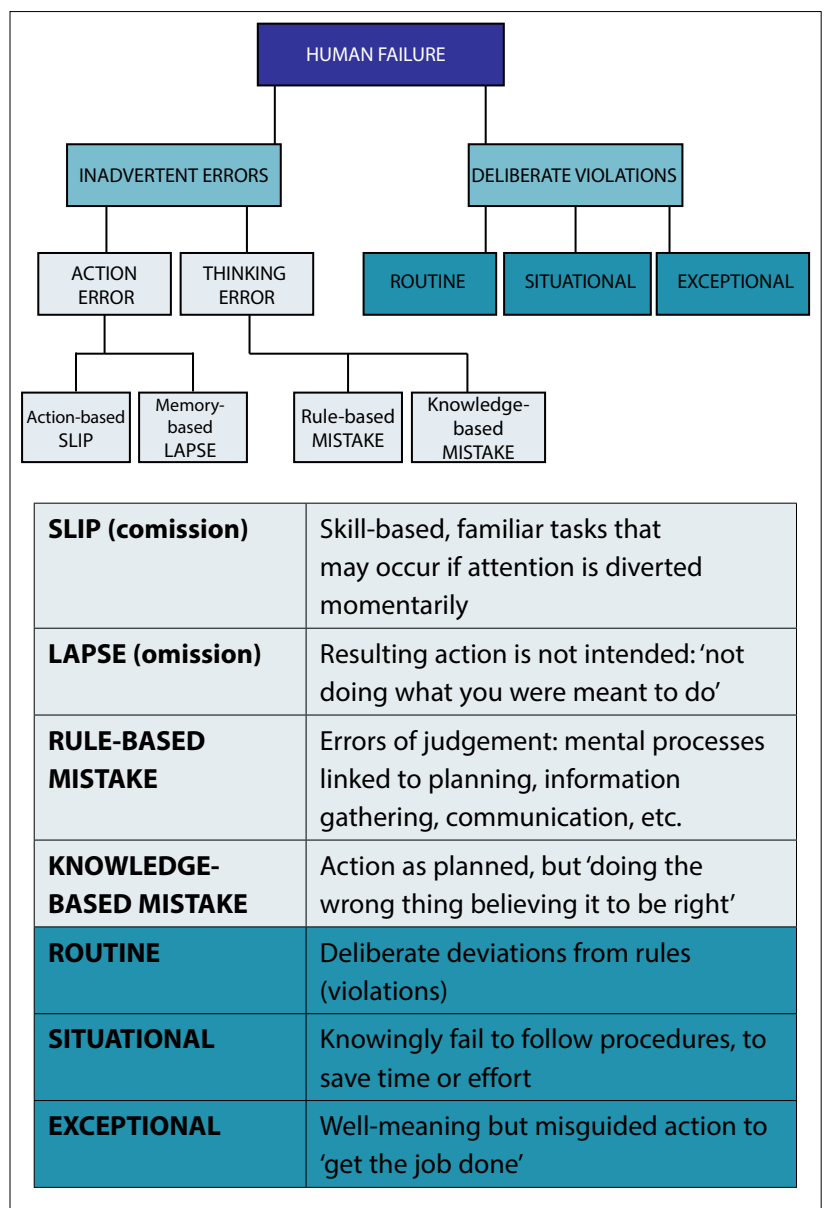

Fig. 1. Human failure types (adapted from Health and Safety Executive ${ }^{[8]}$ ).

- HFs concern the interactions between people and technical components in complex systems. ${ }^{[6]}$

- HFs (or ergonomics) is the scientific discipline concerned with the understanding of interactions among humans and other elements of a system, and the profession that applies theory, principles, data and methods to design in order to optimise human wellbeing and overall system performance. ${ }^{[9]}$

- HFs science attempts to design systems that support human performance and are resilient to unanticipated events. ${ }^{[7]}$

Even though these definitions are generic, they all share 'the primary goal of human factors science to promote efficiency, safety and effectiveness by improving the design of technologies, processes and work systems. ${ }^{[10]}$

There is no definition of HFs specific to wilderness travel scenarios, but to be useful it should comprise both what they are and what they aim to achieve. Such a proposed definition could be that monitoring HFs is the continuous process of identifying those activities and decisions during a risky wilderness endeavour that may prevent or contain human error'. Or, put in another, more practical way, that it is the continuous process of identifying and avoiding the activities, interactions and decisions that may jeopardise a safe and effective response to adverse events. HFs embody a collective habit of continuous and conscious decision-making: all actions are continuously weighed up against present as well as anticipated circumstances, and placed in the context of the team, its functioning, resources and capacity, and the external environment. This active awareness then informs critical personal and team decision-making, which is core to safety. 
Merely observing the interplay of HFs per se does not reduce human error. But by understanding how, in a risky context, HFs allow serious human errors to happen, timely systemic and behavioural safeguards may be introduced. It recognises the need to have checks and balances in place that will diminish those errors, or possibly mitigate their effects if and when they occur.

Broadly speaking, HFs can be grouped into three broad categories:

1. The interpersonal skills of teamwork, leadership and communication

2. The cognitive skills of situational awareness and decision-making

3. The psychophysiology of stress and fatigue.

There are said to be more than 300 HFs, but the so-called 'Dirty Dozen' (Table 1), originally developed for aircraft maintenance crews, ${ }^{[11]}$ are readily transferable to the context of wilderness activities. Most are self-evident, but unless explicitly introduced to the members of a team, and then continuously monitored during the activities of the team, any one or a combination of these factors indicates imminent systemic failure. How then is the awareness of these factors made to function in reality, to improve safety for everyone?

\section{Team building}

Central to the effective implementation of HFs is the concept of working as a team, which relies on the awareness of HFs by all team members, from the leader to the least experienced, to become a strong team. But how is a strong team different from an informal group? Teams are synergistic entities, with mutiple and diverse skill inputs bonded by a team ethic that makes them cohesively responsive to dynamic demands. Table 2 outlines the characteristics that distinguish groups from teams.

A critical component of the success of team building and functioning lies in the balance between leadership and followership.

\section{Leadership}

One of the overarching roles of a leader is to bond an informal group of people into a team to serve a common purpose. In wilderness adventures, that purpose is to enhance safety and to avoid risk and error. The evolution from an informal group to a structured team

\section{Table 1. The 'Dirty Dozen' human factors ${ }^{[11]}$}

\begin{tabular}{|c|c|c|}
\hline $\begin{array}{l}\text { 1. Lack of } \\
\text { communication }\end{array}$ & 5. Complacency & $\begin{array}{l}\text { 9. Lack of } \\
\text { knowledge }\end{array}$ \\
\hline 2. Distraction & 6. Lack of teamwork & 10. Fatigue \\
\hline 3. Lack of resources & 7. Pressure & $\begin{array}{l}\text { 11. Lack of } \\
\text { assertiveness }\end{array}$ \\
\hline 4. Stress & 8. Lack of awareness & 12. Norms \\
\hline
\end{tabular}

should be engaged in and facilitated as soon as possible - as an explicit activity.

To create an effective team, it is necessary that the following 10 aspects, as appropriate, are introduced by the team leader, then discussed, clarified, agreed upon and understood by all team members before the activity starts: ${ }^{[1]}$

1. A clearly defined and maintained aim, or goal

2. Each team member's roles and responsibilities

3. Communication methods

4. Limitations and boundaries of team and individual action

5. Emergency procedures

6. Individual expectations and concerns

7. What defines a successful outcome

8. Debriefing arrangements

9. Team dismissal arrangements

10. Opportunities for questions and clarification.

\section{Followership}

On the other hand, members of the group need to actively engage in followership. Followership is the willingness and capacity of all individuals in a group to actively follow the leader of that group. Importantly, however, followership is not the passive acceptance of guidance, but rather a constructively critical and engaged involvement in making a success of the aims of the team by: ${ }^{[13]}$

1. Actively questioning and evaluating the mission progress

2. Analysing the overall situation

3. Continuously revising one's personal understanding of the mission based on these evaluations and analyses

4. Using assertive but constructive behaviour when necessary

5. Making suggestions

6. Providing relevant information without being asked

7. Asking questions as necessary

8. Confronting ambiguities

9. Stating opinions on decisions/procedures

10. Refusing unreasonable requests.

The best teams in a wilderness context are characterised by 'leaderless leadership' (J H Graafland, unpublished Mountain Club of South Africa Mountain Leadership Course Notes, undated, available from MCSA (Cape Town Section), Hatfield Street, Cape Town, email mcsacapetown@iafrica.com). This occurs when the climate is created for a team to function efficiently without the need for continuous reliance on the team leader. In this role, the team leader's functions are similar to those of a conductor of fully engaged members of an orchestra. Team members may be skilled in very different ways, but they all contribute variously to a cohesive successful outcome. This is in stark contrast to 'groupthink, ${ }^{[14]}$ which is the custom in many groups of thinking or making decisions

Table 2. Characteristics that distinguish an informal group from a strong team (adapted from Chand ${ }^{[12]}$ )

Informal GROUPS
Lack of previous opportunity to engage in collective work requiring
joint effort

Lack of positive synergy to create solutions to complex problems

Parallel performances not greater than the sum of individual inputs Less responsive to dynamic environments

\section{Strong TEAMS}

Members work with both individual and mutual accountability, implementing complementary skills

Evidence of positive synergy:

- bounce ideas off one another

- correct one another's mistakes

- apply diverse knowledge base to problems

- accomplish work too difficult for any individual to achieve

Performances overlap to become greater than sum of individual inputs Flexible response to dynamic environments 
by consensus in a way that discourages creativity or individual responsibility, usually to avoid disharmony and conflict. However, in the 'leaderless' group, differing opinions and options are compared by frank discussion to reach a best solution. The discussion is guided by the team leader, who holds team members' opinions in the same regard as his or her own.

\section{Situational awareness}

Each team member experiences the demands and challenges of the wilderness environment in different ways, and some may therefore recognise circumstances leading to human error before other, even very experienced, team members. The ability to sense 'trouble brewing' before the trouble occurs - to trust and act on gut feel - is called situational awareness (SA).

SA is a skill learned by experience, and is defined as 'the perception of the elements in the environment within a volume of time and space, the comprehension of their meaning, and the projection of their status into the near future ${ }^{\text {?[15] }}$ - in other words, it is the degree of the accuracy of one's perception of environmental reality. It is about every team member monitoring the 'team-in-the-environment' so that potential problems will be detected and corrected before they escalate. SA is the skill of anticipating future contingencies based on the knowledge of the past (experience) and the present (awareness), and then projecting current circumstances into the future.

Fig. 2 illustrates the concept of heightened team SA. In a team of four, each member will have a differing SA of a complex and dynamic process or environment. When all team members are actively situationally aware (A), the intersection of their awareness raises the team's shared or 'distributed' SA to very high levels (the red kite). This is an example of the synergistic effect of good team functioning, which significantly mitigates risk. Yet, as soon as one or two team members are distracted (e.g. No. 4 in team B, who has a slight effect on No. 3), the combined team SA is seriously diminished (the red splinter).

\section{Conclusion: The importance of HFs to mitigate risk}

Risk avoidance relies firstly on adequate levels of experience, ability and competence of team members to deal with current circumstances and recognise potential problems. Secondly, risk avoidance relies on a team understanding that the norm is to communicate any concerns to the team and its leader with assertiveness. Poor knowledge and understanding of potential risks, poor team communication, and the pressure to avoid delays may discourage competent followership. Complacency, distraction and fatigue are widely variable personal

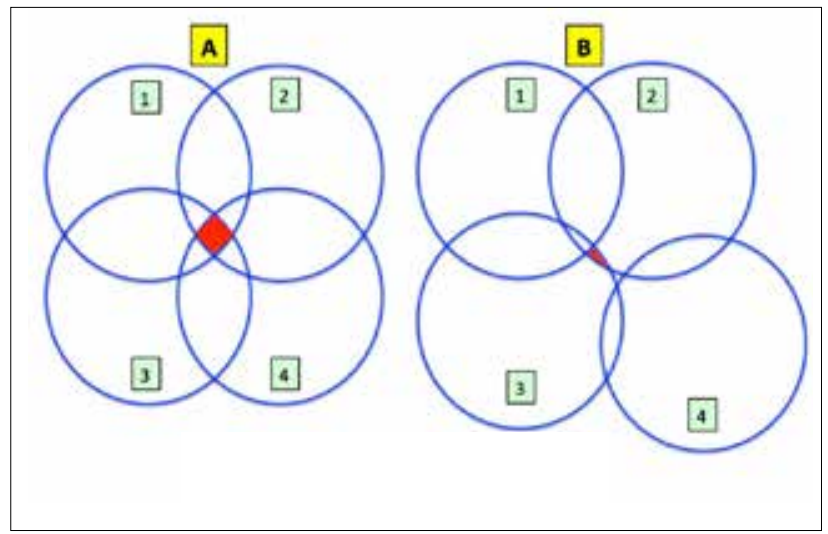

Fig. 2. Team situational awareness in a focused team (A: red kite) and a less focused team (B: red splinter). (Figure developed from an idea of Endsley. ${ }^{[15]}$ ) characteristics that blunt awareness and generate team stress, which handicaps the teamwork required to maintain SA. The maintenance of shared SA is a powerful resource to reduce risk and it, in turn, is directly dependent on these HFs. Ignorance of the influence of HFs will predictably jeopardise optimal team functioning: in a team that is not responsive to the dynamic wilderness environment, SA is significantly weakened, allowing risks to escalate dangerously. In contrast, if attention is paid to the HFs that shape a team, it is possible to avoid or minimise the risk of wilderness accidents.

Finally, when dealing with risk in complex systems, it is worth noting that experience is inferior to currency. Recent exposure to all the demands of the activity is more valuable to the efficient assessment of and response to high-risk events than experience only. We often assume (incorrectly) that activity is thoughtdirected, i.e. proactive rather than reactive. In reality, most activity is simply reactive and little or no attempt is made to think first, particularly in experienced team members. Reactive behaviour is firstly based on old value systems and personal perceptions. More importantly, the second driver of reactive behaviour is experience and the failure to recognise that past performance is not a measure of future success. Experience tends to shoehorn new situations into old solutions. High-risk situations demand experts with currency to devise novel approaches, every time: old skills, but requiring inventive solutions! (Duncan Nel, leadership consultant - personal communication, May 2017.)

\section{Deconstructing the scenario: Comments to illustrate the practical application of HFs}

1. Under the leadership of Pete, an experienced ski-mountaineering guide, a group of six skiers ...

There is adequate time, but no attempt is made at the outset to begin to create a cohesive team from the informal group by a thorough pre-depature briefing.

2. ... there are noticeable differences in the skiing competencies of the team members.

Obvious skill differences are not a problem as long as they are within the skill levels required to complete the Haute Route. If explicitly assessed, they may create opportunities for a team to address and enhance the skills of all, especially those who are less skilled - a shrewd tool to create team cohesion. Awareness and acknowledgement of differing levels of skill is important this allows focus on, compensation for and explicit acceptance of lower levels of skill by all team members, and cognisance of a potential Achilles heel: recognition of the fact that in highrisk environments the group will perform to the level of its least competent member.

3. ... they agree to forego an early finish to the day at the nearby Argentière hut.

Not stopping at the first hut fosters an atmosphere of time pressure, while compromised decision-making skills by fatigued bodies and minds increase the risk of accidents. In contrast, by stopping early, the extra time would offer the opportunity to forge team bonds, and further assess different skill levels in the stress-free ambiance of the hut's safer environment.

4.... their skill differences are further pronounced by the technical challenges ...

An opportunity is missed to replan progress and spend time to teach and demonstrate the special skills required on the difficult glacier terrain, and then descend back to the Argentière hut. This strategy will also validate and reinforce the acceptance of justified delays in progress. 
5. To the further irritation of the competent Sebastian, two of the skiers, Jo and Dave, have to be shown how to use their ski crampons effectively.

This is an opportunity to engage the skilled Sebastian to instruct those who are less skilled, thereby positively redirecting his frustration. An earlier open acknowledgement of lower levels of skill of some team members would have reduced Sebastian's expectations of the group, thereby reducing his frustration at the lack of prowess and progress.

6. There is some delay while Pete explains that he wants all to sideslip the descent while roped, but again Jo and Dave are uncertain precisely how this is done.

Pete could have defused Sebastian's frustration further by asking him to assist in demonstrating how one sideslips while belayed by a rope. One of the more skilled skiers could have done the belaying, thereby further engaging the other team members.

7. ... the mountaintops have disappeared into cloud ...

Clearly, there is a lack of situational awareness. The poor weather is only noted when faced by a tricky descent, a delay is mandatory and stress levels have increased.

8. Pete simply ignores him.

A demonstration of poor leadership skills - Pete's failure to deal with Sebastian's frustration is a recipe for disaster that destroys team cohesion.

9. ... with clear irritation about the 'incompetence' of the others, Sebastian launches off the Col ...

Driven by frustration, Sebastian takes matters into his own hands. Harnessing his energy and drive earlier would have strengthened the team significantly. Even before the accident, the team needed to face a decision: to continue, or ski back down to the Argentière hut. On calm reflection by the team, they probably would have opted to turn back. Had Pete stopped the party and actively invited the opinions of other party members to gain consensus on a change of plan, Sebastian could have contributed to the discussion/consensus and Pete could have gained collective 'buy-in'. Such a considered decision bonds a team well.
10. The team looks on with shock at his abrupt action ...

The team has been passively guided so far, making no spontaneous contributions until Sebastian is driven to an extreme decision. Team co-operation and active followership have not been established, and the team will now be harshly tested. Building an adequate response with a non-cohesive group-thinking team in this situation will be very difficult, and the risks to all have now escalated severely.

'Good judgement is the result of experience and experience the result of bad judgement.' (Mark Twain)

1. Hart CL, Griffith JD. Human error: The principal cause of skydiving fatalities. I Hum Perform Extrem Environ 2003; 7(2), Article 2. http://dx.doi.org/10.7771/2327-2937.1027

2. McCammon I. Human factors in avalanche accidents: Evolution and interventions. In: Schweize J, Gansner C, eds. International Snow Science Workshop. 27 September - 2 October 2009, Davos, Switzerland. Programme and Abstracts. Birmensdorf: Swiss Federal Institute for Forest, Snow and Landscape Research, 2009:644-648. http://www.wsl.ch/dienstleistungen/publikationen/pdf/9893. pdf (accessed 19 June 2017)

3. Wickens CD, Keller JW, Shaw C. Human factors in high-altitude mountaineering. J Hum Perform Extrem Environ 2015;12(1), Article 1. http://dx.doi.org/10.7771/2327-2937.1065

4. Friedman MP, Carterette EC. Human Factors in Aviation. San Diego, Calif.: Academic Press, 2014. 5. Catchpole K. Spreading human factors expertise in healthcare: Untangling the knots in people an systems. Qual Saf Health Care 2013;22(10):1-5. http://dx.doi.org/10.1136/bmjqs-2013-002036

6. Catchpole K, Goldman A, Lyons M, Maran N, Shearer H, Rogers H. Human Factors Training in the National Health Service: A Scoping Study. Leeds, UK: NHS Institute for Innovation and Improvement, 2010 .

7. Scanlon MC, Karsh BT. Value of human factors to medication and patient safety in the intensive care unit. Crit Care Med 2010;38(6 Suppl):S90-S96. http://dx.doi.org/10.1097/CCM.0b013e3181dd8de2 Health and Safety Executive (UK). Understanding human failure. http://www.hse.gov.uk/ Health and Safety Executive (UK). Understanding human failure. htt
construction/lwit/assets/downloads/human-failure.pdf(accessed 9 May 2017).

construction//wit/assets/downloads/human-failure.pdf (accessed 9 May 2017 ).
Wikipedia. Human factors and ergonomics. https://en.wikipedia.org/w/index.php?title=Human Wikipedia. Human factors and ergonomics. https://en.wikipedia.or
factors and_ergonomics\&oldid=778376557 (accessed 9 May 2017).

10. Russ AL, Fairbanks RJ, Karsh B-T, Militello LG, Saleem JJ, Wears RL. The science of human Russ AL, Fairbanks RJ, Karsh B-T, Militello LG, Saleem JJ, Wears RL. The science of human
factors: Separating fact from fiction. BMJ Qual Saf 2013;22(10). http://dx.doi.org/10.1136 bmjqs-2012-001450

11. Skybrary: The single point link to aviation safety knowledge. The Human Factors 'Dirty Dozen' http://www.skybrary.aero/index.php/The_Human_Factors_\%22Dirty_Dozen\%22\#cite_note-3 (accessed 9 May 2017)

12. Chand S. Group dynamics: Its characteristics, stages, types, factors, team building and other details. http://www.yourarticlelibrary.com/management/group-dynamics-its-characteristics-stages-types and-other-details-management/5363/ (accessed 4 May 2017).

13. Shimanski C. Situational Awareness in Search and Rescue Operations. Training manuscript of the Colorado Mountain Rescue Team. Denver, Colo.: Mountain Rescue Association, 2015.

4. Wikipedia. Groupthink. https://en.wikipedia.org/w/index.php?title=Groupthink\&oldid=775857382 (accessed 11 May 2017)

15. Endsley MR. Toward a theory of situation awareness in dynamic systems. Hum Factors J Hum Factors Ergon Soc 1995;37(1):32-64. http://dx.doi.org/10.1518/001872095779049543 